\title{
S-Ketamine As An Adjuvant in Patient-controlled Intravenous Analgesia for Prevention of Postpartum Depression: A Randomized Controlled Trial
}

\section{Yaqian Han}

Department of Anesthesiology and Perioperative Medicine, Henan University People's Hospital; Henan Provincial People's Hospital, Zhengzhou, China

\section{Pule Li}

Department of Anesthesiology and Perioperative Medicine, Henan Provincial People's Hospital; People's Hospital of Zhengzhou University, Zhengzhou, China

\section{Mengrong Miao}

Department of Anesthesiology and Perioperative Medicine, Henan Provincial People's Hospital; People's Hospital of Zhengzhou University, Zhengzhou, China

\section{Yuan Tao}

Department of Anesthesiology and Perioperative Medicine, Henan Provincial People's Hospital; People's Hospital of Zhengzhou University, Zhengzhou, China

\section{Kang Xia}

Department of Anesthesiology and Perioperative Medicine, Henan Provincial People's Hospital; People's Hospital of Zhengzhou University, Zhengzhou, China

\section{Jiaqiang Zhang ( $\sim$ Zhangjiq@zzu.edu.cn )}

Department of Anesthesiology and Perioperative Medicine, Henan Provincial People's Hospital; People's Hospital of Zhengzhou University, Zhengzhou, China

\section{Research Article}

Keywords: cesarean section, patient-controlled Intravenous analgesia, PCIA, postpartum depression, Sketamine, puerperal

Posted Date: December 16th, 2021

DOI: https://doi.org/10.21203/rs.3.rs-1071295/v1

License: (c) (i) This work is licensed under a Creative Commons Attribution 4.0 International License. Read Full License 


\section{Abstract}

(1) Background: Postpartum depression (PPD) is a common complication after cesarean section. Recent studies have shown that intravenous S-ketamine during surgery could be effective in preventing PPD. However, no evidence shows S-ketamine used in patient-controlled intravenous analgesia (PCIA) could reduce the incidence of PPD. Our aim was to explore the effect of S-ketamine as an adjuvant in patientcontrolled intravenous analgesia (PCIA) for prevention of postpartum depression.

(2) Methods: In a single center, 375 parturients scheduled to undergo cesarean section were recruited and randomly assigned to two groups: Control group (C group) or S-ketamine group (S group). Parturients in both groups received PCIA, the formula of Group C: sufentanil $2 \mu \mathrm{g} / \mathrm{kg}+$ tropisetron $10 \mathrm{mg}, \mathrm{S}$ group was the same as $C$ group except $0.5 \mathrm{mg} / \mathrm{kg}$ S-ketamine. The primary outcome was the incidence of PPD measured by the Edinburgh Postnatal Depression Scale (EPDS) after surgery. The secondary outcomes were EPDS scores, Visual analogue scale (VAS) scores, and Ramsay Sedation Scale (RSS) scores, and incidence of related adverse events.

(3) Results: A total of 275 puerpera were finally included and randomly assigned to two groups. The incidence of depression at postoperative 3,14 , 28days in C group and S group were $17.6 \%$ vs $8.2 \%$, $\mathrm{P}<0.05 ; 24.2 \%$ vs $9.8 \%, \mathrm{P}<0.05$, and $19.0 \%$ vs $17.2 \%, \mathrm{P}=0.76$, respectively). As for EPDS scores, $\mathrm{C}$ group and $S$ group at 3,14 , and 28 days after cesarean were 7.65 $\pm 3.14 v s 6.00 \pm 2.47, p<0.05,7.62 \pm 3.14 v s 6.38 \pm 2.67$, $p<0.05$, and $7.35 \pm 3.17 v s 6.90 \pm 2.78, p=0.15$, respectively. Adverse events such as headache and nausea were $3.3 \%$ vs $4.1 \%, p=0.755 ; 5.9 \%$ vs $8.2 \%, p=0.481$.

(4) Conclusions: $0.01 \mathrm{mg} / \mathrm{kg} / \mathrm{h}$ S-ketamine as an adjuvant in patient-controlled intravenous analgesia can significantly reduce the incidence of postpartum depression within 14 days and relieve postoperative pain within $48 \mathrm{~h}$ after cesarean section, without increasing the incidence of adverse reactions.

Trial registration: ChiCTR, ChiCTR2100050263®retrospectively registered. Registered 24/08/2021.

\section{Introduction}

Postpartum depression (PPD) is a common psychosocial disorder that can have adversely affect the life of the mother, as well as the baby and family[1]. It has been reported the incidence of PPD is $1 \%-52.1 \%$ in China[2, 3], and severe depression that requires hospitalization is more likely to occur after childbirth than in women at any other time[4], because childbirth is a powerful trigger for mania and psychosis, and episodes at this period could substantially increase the risk of suicide, which is a leading cause of maternal death[5]. Therefore, reducing the occurrence of puerperal getting PPD is necessary.

In obvious studies, ketamine has been proved to be a powerful drug to release depression and reduce suicidal tendency in depressed patients[1, 6, 7]. Some reports have proved that the intravenous injection of ketamine during cesarean section could be effective in preventing postpartum depression until 3 days to 6 weeks $[1,3,8]$. S-ketamine, the dextral resolution of ketamine, its anesthetic effect is twice as 
effective as the racemic mixture and about three times as potent as (R)-ketamine[9-13]. Besides, as the side effects of ketamine are dose-dependent, S-ketamine has a lower incidence of adverse events than ketamine when we aimed to arrive at the same sub-anesthetic effect[14]. So we presume that S-ketamine used for PCIA may be a good choice as it can continuedly to infuse for 2 days at about $0.01 \mathrm{mg} / \mathrm{kg} / \mathrm{h}$. Therefore, we hypothesized that S-ketamine as an adjuvant in patient-controlled intravenous analgesia can prevent postpartum depression.

\section{Methods}

\section{Study design}

The research scheme was approved by the Ethics Committee of Henan Provincial people's Hospital ([2019] 53), Henan, China, and registered in the China Clinical trial Registration Center, registration number:ChiCTR2100050263, (24/08/2021,retroactive registration). All subjects received informed written consent.

\section{Participants}

Parturients from 1 September 2019 to 15 July 2020 in Henan Provincial People's Hospital were enrolled. Eligibility criteria included the following: (1) undergoing cesarean delivery in our hospital, (2) the age of puerperal is $\geq 18$ and $\leq 45$, (3) the birth age is $\geq 36$ and $\leq 42$ weeks, (4) BMl $17-36 \mathrm{~kg} / \mathrm{m} 2$, and (5) ASA grade ranged $\mathbb{\bigotimes} \bigotimes$; Exclusion criteria included: (1) The puerperal has experienced depression and has been diagnosed as depression by a psychiatrist before, (2) the pregnant has experienced domestic violence before, (3) the pregnant with a serious obstetric complication or serious foundational diseases, (4) the newborn has serious genetic or congenital diseases, and (5) multiple pregnancies.

\section{Randomization and blinding}

Parturients were randomly assigned in a 1:1 ratio to S-group or C-group using SPSS 25.0. Parturients signed informed consent forms by themselves on the day of undergoing cesarean. Anesthesiologists, parturients, follow-up investigators were blinded throughout the study period. Staff who distribute PCIA generated the random allocation sequence, knew the group assignment of patients.

\section{Procedures}

All parturients underwent spinal anesthesia at L3-L4 or L2-L3 level and received patient-controlled anesthesia after surgery. The spinal anesthesia solution was $1 \%$ ropivacaine $2 \mathrm{~mL}+10 \%$ glucose $1 \mathrm{~mL}$, anesthesiologist controlled at $1 \mathrm{ml} / 5 \mathrm{~s}$ to arrive block level up to T4-T6.. At the end of surgery, all parturients would receive NSAIDs drug (propacetamol $2.0 \mathrm{~g}$ intravenous drip) and transversus abdominis plane (TAP) nerve block at ultrasound-guided for preemptive analgesia. Parturients in the $\mathrm{C}$ group received a PCIA with sufentanil $2 \mu \mathrm{g} / \mathrm{kg}$ and tropisetron $10 \mathrm{mg}$ while parturients in the S group received Sketamine $0.5 \mathrm{mg} / \mathrm{kg}$, sufentanil $2 \mu \mathrm{g} / \mathrm{kg}$, and tropisetron $10 \mathrm{mg}$. The volume of the PCIA $\mathrm{n}$ both groups is 
$100 \mathrm{~mL}$, which can support $48 \mathrm{~h}$ 's anesthesia with the infusion of $2 \mathrm{~mL} / \mathrm{h}, \mathrm{PCIA}$ doses $2 \mathrm{ml} / \mathrm{h}$, maximum dose $10 \mathrm{ml} / \mathrm{h}$, blocked time is $15 \mathrm{~min}$.

Parturients were followed up by investigators at $4 \mathrm{~h}$ (T1), 8h (T2), 12h (T3), 24h (T4),48h (T5) after cesarean, and $3,14,28$ days postpartum. The VAS and RSS scores were administered at $4 \mathrm{~h}, 8 \mathrm{~h}, 12 \mathrm{~h}, 24 \mathrm{~h}$, $48 \mathrm{~h}$ after cesarean. EPDS was administered on days $3,14,28$ postoperatively. The EPDS contains ten questions with four sub-answers correspondingly and 0-3 points for each answer, the total score is 0-30. In our study, EPDS score $\geq 10$ was considered to diagnose postpartum depression.

Any discomfort (headache, nausea, dizziness, drowsiness, and vomit, et al) will be recorded during they use PCIA.

The scores of EPDS were tested before surgery, 3 days, 14 days, and 28 days after surgery. On the days of $3,14,28$ days after cesarean, parturients were contacted by phone or WeChat to complete EPDS by investigators.

\section{Outcome measures}

The incidence of PPD is our primary outcome. The secondary outcomes were scores of EPDS at days of $3,14,28$ days after cesarean section. RSS scale and VAS scores were assessed at $4 \mathrm{~h}(\mathrm{~T} 1), 8 \mathrm{~h}(\mathrm{~T} 2), 12 \mathrm{~h}(\mathrm{~T} 3), 24 \mathrm{~h}(\mathrm{~T} 4)$, and $48 \mathrm{~h}(\mathrm{~T} 5)$ postpartum.

Adverse events including headache, nausea, dizziness, drowsiness and vomit were recorded during parturients using PCIA.

\section{Sample size and statistical analysis}

According to previous studies[2, 3], when the EPDS score $\geq 10$ was used as the detection threshold of postpartum depression, the prevalence rate of postpartum depression in China is $28.2 \%$. We assumed that ketamine used for PCIA will reduce postpartum depression to $15 \%$; with $80 \%$ statistical power, $a=$ 0.05 for two-tailed tests, PASS 15.0 software yielded a sample size of 300 (150 parturients in each study arm); assuming a $20 \%$ drop-out rate, the sample size was finally established at 375 .

Continuous variables are presented as the mean \pm standard deviation or as the median (min and max range); t-test or Mann-Whitney U test was performed for between-group comparisons. Categorical variables are presented as percentages; these data were compared using X2 test or Fisher's exact test. The SPSS 25.0 software was used for the statistical analysis. A value of $P<0.05$ was considered statistically significant for two-tailed tests.

\section{Results}

During the time of 1 September 2019 to 15 July 2020, a total of 451 parturients were eligible, 71 parturients chose vaginal delivery for various causes. So 380 were enrolled in this trial, and 53 parturients refused to continuously participate in this study after cesarean section. Thus, 327 parturients were 
ultimately enrolled in this trial. During 28 days' follow-up, 52 subjects were lost. So, 275 parturients were finally included in analyzed (Figure 1).

\section{Baseline characteristics}

The baseline characteristics of subjects were listed in Table 1 and were well balanced between the $S$ group and $\mathrm{C}$ group.

Table 1

Characteristics of the parturients between two groups

\begin{tabular}{|c|c|c|c|}
\hline & C group $(n=153)$ & $S$ group $(n=122)$ & P-value \\
\hline Age, years & $31.85 \pm 4.16$ & $31.64 \pm 3.93$ & 0.71 \\
\hline ASA physical status, $\mathbb{\nabla} / \mathbb{\square}$ & $39 / 114$ & $31 / 91$ & 1.0 \\
\hline $\mathrm{BMI}, \mathrm{kg} / \mathrm{m}^{2}$ & $26.89 \pm 2.58$ & $27.08 \pm 2.95$ & 0.63 \\
\hline Time of surgery, min & $51.59 \pm 11.07$ & $53.60 \pm 9.99$ & 0.31 \\
\hline Blood loss, ml & $301.83 \pm 98.47$ & $320.90 \pm 121.26$ & 0.73 \\
\hline EPDS score before surgery & $6.54 \pm 2.35$ & $6.72 \pm 2.25$ & 0.48 \\
\hline Primipara, yes/no & $114 / 39$ & $84 / 38$ & 0.30 \\
\hline Education background & & & 0.19 \\
\hline Primary school & 3 & 2 & \\
\hline Secondary school & 26 & 10 & \\
\hline High school & 48 & 41 & \\
\hline University & 76 & 69 & \\
\hline Planned pregnancy, yes/no & $137 / 16$ & $108 / 14$ & 0.34 \\
\hline Gender, boys/girls & $81 / 72$ & $77 / 45$ & 0.66 \\
\hline Infant feeding ${ }^{1}$ & & & 0.12 \\
\hline Maternal & 105 & 97 & \\
\hline Mixed & 34 & 17 & \\
\hline Artificial & 14 & 8 & \\
\hline Major family accident ${ }^{1,2}$ & 1 & 2 & 0.59 \\
\hline
\end{tabular}


For the primary outcome of our study, the occurrence of depression between two groups, the $\mathrm{S}$ group was significantly less than the $C$ group at 3 days and 14 days after cesarean (( $17.6 \%$ vs $8.2 \%$, $\mathrm{P}<0.05 ; 24.2 \% v s 9.8 \%, \mathrm{P}<0.05$, respectively), but no difference at 28 days (19.0\%vs17.2, $\mathrm{P}>0.05)$. (Figure 2).

\section{Secondary outcome}

The secondary outcome, EPDS scores were similar and defined as no depression between two groups before cesarean $(6.54 \pm 2.35 \mathrm{vs} 6.72 \pm 2.25, \mathrm{P}=0.508)$. However, we found significant differences in the score of EPDS at the time of 3 days $(7.65 \pm 3.14 v s 6.00 \pm 2.47, p<0.001), 14$ days $(7.62 \pm 3.14 v s 6.38 \pm 2.67$, $\mathrm{p}<0.001)$ after cesarean. 28 days of EPDS scores have assessed no difference between the two groups (7.35 $\pm 3.17 v s 6.90 \pm 2.78, p=0.217)$. (Figure 3 )

As for VAS scores of $\mathrm{T} 1, \mathrm{~T} 2, \mathrm{~T} 3, \mathrm{~T} 4$, there were significant differences between the two groups at various times, furthermore, the $S$ group was always less than the $C$ group. (Figure $4 a$ ) RSS scores were recorded at the time of $4 \mathrm{~h}(\mathrm{~T} 1), 8 \mathrm{~h}(\mathrm{~T} 2), 12 \mathrm{~h}(\mathrm{~T} 3), 24 \mathrm{~h}(\mathrm{~T} 4)$ postpartum, and they were similar except T4 $(1.99 \pm 0.14 \mathrm{vs}$ $2.05 \pm 0.22, p=0.015$ ) (Figure $4 b)$. The occurrence of adverse events between the two groups are no different (Table 2)

Table 2

Adverse events during using PCIA

\begin{tabular}{|lllll|}
\hline Adverse events & C-group (\%) & S-group (\%) & Total (\%) & P value \\
\hline Headache & $5(3.3)$ & $5(4.1)$ & $10(3.6)$ & 0.755 \\
\hline Nausea & $9(5.9)$ & $10(8.2)$ & $19(6.9)$ & 0.481 \\
\hline Dizzy & $14(9.2)$ & $15(12.3)$ & $29(10.5)$ & 0.434 \\
\hline Drowsiness & $10(6.5)$ & $13(10.7)$ & $23(8.4)$ & 0.274 \\
\hline Vomit & $9(5.9)$ & $7(5.7)$ & $16(5.8)$ & 0.585 \\
\hline
\end{tabular}

\section{Discussion}

In this trial, we found that $0.01 \mathrm{mg} / \mathrm{kg} / \mathrm{h} \mathrm{S}$-ketamine used in PCIA for women who undergo cesarean can reduce the incidence of postpartum depression and scores of EPDS within 14 days effectively, simultaneously not increasing side reaction. Besides, PPD was increased along with time flowed within 1 month in both groups we observed, which is consistent with the previous studies[1, 15, 16].

Some reports have shown ketamine's short and rapid effect on reducing parturient's depression symptoms $[12,17,18]$. However, these reports differed from our study to some extent. In a study by Yao. $J$ et al[8], healthy women scheduled for cesarean delivery were received intravenous ketamine $0.25 \mathrm{mg} / \mathrm{kg}$ intraoperative but not postoperative. interestingly, their results showed that PPD was effectively reduced at 1 week postpartum, instead of at 2 weeks and 4 weeks. Besides, the prevalence of adverse events such 
as headache, hallucination, and dizziness were higher in the ketamine group during the operation. The reason why their results were inconsistent with ours may be because it was only using ketamine once in subanesthetic dose instead of continuing intravenous administrate. our study chose a continuous infusion of $0.01 \mathrm{mg} / \mathrm{kg} / \mathrm{h}$ ketamine used in PCIA, which can last a long time to prevent or therapy depression. The following methodological differences between the current trial and Yao's trial might partially explain the discrepant findings: intervention differ, compliance with trial protocols, population local distribution, rigor in depression ascertainment.

EPDS scores are usually used to screen for postpartum depression when scores are $\geq 10[19,20]$, and it is suggested that depression be tested or diagnosed before 6 weeks postpartum[21-25]. The questionnaire we used was the Chinese version of EPDS, which was proved to be well-validated to Chinese women. In a previous study[16], parturients who were given ketamine $0.5 \mathrm{mg} / \mathrm{kg}$ at $10 \mathrm{~min}$ after childbirth, and $160 \mathrm{mg}$ ketamine in PCIA postoperative, found that it effectively reduced postpartum depression and postpartum blue in 4 days after cesarean. It can support our result that the incidence of PPD in the S group reduced significantly at 3 days and 14 days postoperatively to a certain extent.

Recent studies have demonstrated that a low dose of ketamine can reduce the incidence of anesthetic side reactions[14]. A review recently advised that parturients outside the perioperative setting could use ketamine as an analgesic or sedative to mitigate mood and depression[7], which was corresponded to our results. In our study, the VAS score was significantly lower in S-group during they used PCIA. The incidence of headache, nausea, dizziness, drowsiness, and vomit decreased to a certain extent, though no significant difference was found.

Earlier research showed that single doses of intravenous S-ketamine or ketamine use during cesarean section delivery may not affect the breastfed infant or lactation[2]. The dose of S-ketamine we administrated is lower than sub-anesthetic, so we believe $0.5 \mathrm{mg} / \mathrm{Kg}$ S-ketamine diluted in $100 \mathrm{ml}$ saline intravenous lasts $48 \mathrm{~h}$ is safe for both mother and infant[26, 27].

This trial also has some limitations. First, the trial sample size is not big enough, and the population is residents. Maybe we should conduct multicenter studies to enroll more subjects in future studies. Second, in studies of Salloum et al, time to relapse depression after successful treatment of ketamine appears to follow a dose-response relationship, where higher dosage leads to increased time to relapse[28, 29]. We chose the dose of S-ketamine in PCIA as $0.5 \mathrm{mg} / \mathrm{Kg}$, so we don't know if more or fewer doses could show a better effect on preventing postpartum depression. Future research could explore a better dose of Sketamine as an adjuvant in PCIA, which to guide doctors to prevent PPD. Third, we followed up with parturients until 28 days postpartum, because of more mixed factors such as stressful life events, poor social support, poor marital relationship, personal vulnerability, and low socioeconomic status[2, 15, 3035], which could influence the future incidence of PPD along with time flow. By the way, we recorded these elements in 28 days after cesarean section and there was consistency between the two groups. Maybe those factors could influence our primary outcomes but we did not record them. Future studies should consider involving these elements in baseline characteristics. 


\section{Conclusions}

In conclusion, $0.01 \mathrm{mg} / \mathrm{kg} / \mathrm{h}$ S-ketamine as an adjuvant in patient-controlled intravenous analgesia can significantly reduce the incidence of postpartum depression within 14 days and relieve postoperative pain within $48 \mathrm{~h}$ after cesarean section, without increasing the incidence of adverse reactions. This finding supports the efficiency and safety of S-ketamine used in PCIA to reduce postpartum depression. Future researches should include a larger number of parturients in similar studies, and the interactional relationships between serologic indexes and precipitating risk factors for postpartum depression should be explored.

\section{Abbreviations}

ASA: American society of anesthesiology; EPDS: Edinburgh Postnatal Depression Scale; PCIA: patientcontrolled Intravenous analgesia; PPD: Postpartum depression; RSS: Ramsay Sedation Scale; VAS: Visual Analogue Scale

\section{Declarations}

\section{Acknowledgements}

We would like to acknowledge the parturients involved in this study for their participation, and thank all members in the study for their support and help.

\section{Author Contributions}

Conceptualization-Yaqian Han and Pule Li; methodology-Mengrong Miao; formal analysis-Yuan Tao; writing-original draft preparation-Yaqian Han; writing-review and editing-Pule Li and Jiaqiang Zhang; visualization-Xia Kang; project administration-Jiaqiang Zhang; funding acquisition-Jiaqiang Zhang. All authors have read and agreed to the published version of the manuscript.

\section{Funding}

This research was funded by the Natural Science Foundation of Henan Province (No. 202300410353) and the Health Science and Technology innovation talents Project of Henan Province (No.YXKC2020001).

\section{Availability of data and materials}

The datasets generated during the current study are not publicly available due the regulation of data management of Henan Provincial People's Hospital, but are available from the corresponding author on reasonable request. 


\section{Ethics approval and consent to participate}

The study protocol was approved by the Henan Provincial People's Hospital Ethics Committee ([2019]53), Henan, China, and registered in the Chinese Clinical Trial Registry (registration no. ChiCTR2100050263】 retrospectively registered) (also see https://www.chictr.org.cn/showproj.aspx?proj=129088). Informed written consent was obtained from all subjects. Data are available on reasonable request. Data will be available (following deidentifcation of the participant data) on request via email to the corresponding author.

\section{Institutional Review Board Statement}

The study was conducted according to the guidelines of the Declaration of Helsinki, and approved by the Ethics Committee Henan Provincial People's Hospital Ethics Committee (([2019]53), approval date: August 21, 2019). All women involved in this study filled out informed consent and data treatment forms to enter the study, in accordance with the ethical standards of the Ethics Committee.

\section{Informed Consent Statement}

Informed consent was obtained from all subjects involved in the study.

\section{Consent for publication}

Not Applicable.

\section{Competing interest}

The authors declare that they have no competing interests.

\section{Author details}

${ }^{1}$ Department of Anesthesiology and Perioperative Medicine, Henan University People's Hospital; Henan Provincial People's Hospital, Zhengzhou, China.

${ }^{2}$ Department of Anesthesiology and Perioperative Medicine, Henan Provincial People's Hospital; People's Hospital of Zhengzhou University, Zhengzhou, China.

\section{References}

1. Alipoor M, Loripoor M, Kazemi M, Farahbakhsh F, Sarkoohi A: The effect of ketamine on preventing postpartum depression. J Med Life 2021, 14(1):87-92. http://doi.org/10.25122/jml-2020-0116

2. Yamamoto N, Abe Y, Arima K, Nishimura T, Akahoshi E, Oishi K, Aoyagi K: Mental health problems and influencing factors in Japanese women 4 months after delivery. J Physiol Anthropol 2014, 33(1):32.http://doi.org/10.1186/1880-6805-33-32 
3. Xu Y, Li Y, Huang X, Chen D, She B, Ma D: Single bolus low-dose of ketamine does not prevent postpartum depression: a randomized, double-blind, placebo-controlled, prospective clinical trial. Arch Gynecol Obstet 2017, 295(5):1167-1174

4. Morris LS, Costi S, Tan A, Stern ER, Charney DS, Murrough JW: Ketamine normalizes subgenual cingulate cortex hyper-activity in depression. Neuropsychopharmacology 2020, 45(6):975-981 http://doi.org/10.1038/s41386-019-0591-5

5. Jones I, Chandra PS, Dazzan P, Howard LM: Bipolar disorder, affective psychosis, and schizophrenia in pregnancy and the post-partum period. Lancet 2014, 384(9956):17891799.http://doi.org/10.1016/s0140-6736(14)61278-2

6. Zhan Y, Zhang B, Zhou Y, Zheng W, Liu W, Wang C, Li H, Chen L, Yu L, Walter M et al: A preliminary study of anti-suicidal efficacy of repeated ketamine infusions in depression with suici dal ideation. $J$ Affect Disord 2019, 251:205-212. http://doi.org/10.1016/j.jad.2019.03.071

7. Reinert J, Parmentier BL: Effect of Perioperative Ketamine on Postoperative Mood and Depression: A Review of the Literature. Expert Rev Clin Pharmacol 2021, 14(1):25-32.

http://doi.org/10.1080/17512433.2021.1855142

8. Yao J, Song T, Zhang Y, Guo N, Zhao P: Intraoperative ketamine for reduction in postpartum depressive symptoms after cesarean delivery: A double-blind, randomized clinical trial. Brain Behav 2020, 10(9):e01715.http://doi.org/10.1002/brb3.1715

9. Zanos P, Moaddel R, Morris P, Riggs L, Highland J, Georgiou P, Pereira E, Albuquerque E, Thomas C, Zarate $\mathrm{C}$ et al: Ketamine and Ketamine Metabolite Pharmacology: Insights into Therapeutic Mechanisms. Pharmacological reviews 2018, 70(3):621-660.http://doi.org/10.1124/pr.117.015198

10. Sinner B, Graf B: Ketamine. Handbook of experimental pharmacology 2008(182):313333.http://doi.org/10.1007/978-3-540-74806-9_15

11. Wang J, Huang J, Yang S, Cui C, Ye L, Wang SY, Yang GP, Pei Q: Pharmacokinetics and Safety of Esketamine in Chinese Parturients Undergoing Painless Gastroscopy in Comparison with Ketamine: A Randomized, Open-Label Clinical Study. Drug Des Devel Ther 2019, 13:41354144.http://doi.org/10.2147/dddt.S224553

12. Krystal JH, Charney DS, Duman RS: A New Rapid-Acting Antidepressant. Cell 2020, 181(1):7.http://doi.org/10.1016/j.cell.2020.02.033

13. Hashimoto $\mathrm{K}$ : Molecular mechanisms of the rapid-acting and long-lasting antidepressant actions of (R)-ketamine. Biochem Pharmaco/ 2020, 177:113935. http://doi.org/10.1016/j.bcp.2020.113935

14. Zou L, Tian SY, Quan X, Ye TH: Psychedelic effects of subanesthetic doses of ketamine. Zhongguo Yi Xue Ke Xue Yuan Xue Bao 2009, 31(1):68-72.

15. Gaudet C, Wen SW, Walker MC: Chronic perinatal pain as a risk factor for postpartum depression symptoms in Canadian women. Can J Public Health 2013, 104(5):e375387.http://doi.org/10.17269/cjph.104.4029

16. Ma JH, Wang SY, Yu HY, Li DY, Luo SC, Zheng SS, Wan LF, Duan KM: Prophylactic use of ketamine reduces postpartum depression in Chinese women undergoing cesarean section. Psychiatry Res 
2019, 279:252-258.http://doi.org/10.1016/j.psychres.2019.03.026

17. Lascelles K, Marzano L, Brand F, Trueman H, McShane R, Hawton K: Effects of ketamine treatment on suicidal ideation: a qualitative study of parturients' accounts followi ng treatment for depression in a UK ketamine clinic. BMJ Open 2019, 9(8):e029108. http://doi.org/10.1136/bmjopen-2019029108

18. Wilkinson ST, Ballard ED, Bloch MH, Mathew SJ, Murrough JW, Feder A, Sos P, Wang G, Zarate CA, Jr., Sanacora G: The Effect of a Single Dose of Intravenous Ketamine on Suicidal Ideation: A Systematic Review and Individual Participant Data Meta-Analysis. Am J Psychiatry 2018, 175(2):150158.http://doi.org/10.1176/appi.ajp.2017.17040472

19. Hinkle SN, Buck Louis GM, Rawal S, Zhu Y, Albert PS, Zhang C: A longitudinal study of depression and gestational diabetes in pregnancy and the postpartum period. Diabetologia 2016, 59(12):25942602.http://doi.org/10.1007/s00125-016-4086-1

20. Chen $Y, Y e X$, Wu H, Huang X, Ke C, Chen Y, Wu H, Wu X: Association of Postpartum Pain Sensitivity and Postpartum Depression: A Prospective Observational Study. Pain Ther 2021.http://doi.org/10.1007/s40122-021-00325-1

21. Costafreda SG, Chu C, Ashburner J, Fu CH: Prognostic and diagnostic potential of the structural neuroanatomy of depression. PLoS One 2009, 4(7):e6353.http://doi.org/10.1371/journal.pone.0006353

22. Meltzer-Brody S, Boschloo L, Jones I, Sullivan PF, Penninx BW: The EPDS-Lifetime: assessment of lifetime prevalence and risk factors for perinatal depression in a large cohort of depressed women. Arch Womens Ment Health 2013, 16(6):465-473.http://doi.org/10.1007/s00737-013-0372-9

23. Grace SL, Evindar A, Stewart DE: The effect of postpartum depression on child cognitive development and behavior: a review and critical analysis of the literature. Arch Womens Ment Health 2003, 6(4):263-274.http://doi.org/10.1007/s00737-003-0024-6

24. Cox JL, Holden JM, Sagovsky R: Detection of postnatal depression. Development of the 10-item Edinburgh Postnatal Depression Scale. Br J Psychiatry 1987, 150:782786.http://doi.org/10.1192/bjp.150.6.782

25. Murrough JW, losifescu DV, Chang LC, Al Jurdi RK, Green CE, Perez AM, Iqbal S, Pillemer S, Foulkes A, Shah A et al: Antidepressant efficacy of ketamine in treatment-resistant major depression: a two-site randomized controlled trial. Am J Psychiatry 2013, 170(10):1134-

1142.http://doi.org/10.1176/appi.ajp.2013.13030392

26. Singh JB, Fedgchin M, Daly E, Xi L, Melman C, De Bruecker G, Tadic A, Sienaert P, Wiegand F, Manji H et al: Intravenous Esketamine in Adult Treatment-Resistant Depression: A Double-Blind, DoubleRandomization, Placebo-Controlled Study. Biol Psychiatry 2016, 80(6):424431.http://doi.org/10.1016/j.biopsych.2015.10.018

27. Lei Y, Liu H, Xia F, Gan S, Wang Y, Huo W, Wang Q, Ji F: Effects of Esketamine on Acute and Chronic Pain After Thoracoscopy Pulmonary Surgery Under General Anesthesia: A Multicenter-Prospective, 
Randomized, Double-Blind, and Controlled Trial. Front Med (Lausanne) 2021, 8:693594.http://doi.org/10.3389/fmed.2021.693594

28. Salloum NC, Fava M, Hock RS, Freeman MP, Flynn M, Hoeppner B, Cusin C, losifescu DV, Trivedi MH, Sanacora $\mathrm{G}$ et al: Time to relapse after a single administration of intravenous ketamine augmentation in unipolar treatment-resistant depression. J Affect Disord 2020, 260:131-139. http://doi.org/10.106/j.jad.2019.09.017

29. Singh JB, Fedgchin M, Daly EJ, De Boer P, Cooper K, Lim P, Pinter C, Murrough JW, Sanacora G, Shelton RC et al: A Double-Blind, Randomized, Placebo-Controlled, Dose-Frequency Study of Intravenous Ketamine in Parturients With Treatment-Resistant Depression. Am J Psychiatry 2016, 173(8):816-826.http://doi.org/10.1176/appi.ajp.2016.16010037

30. Levine JA, Bukowinski AT, Sevick CJ, Mehlhaff KM, Conlin AMS: Postpartum depression and timing of spousal military deployment relative to pregnancy and delivery. Archives of Gynecology and Obstetrics 2015, 292(3):549-558.http://doi.org/10.1007/s00404-015-3672-7

31. Norhayati MN, Nik Hazlina NH, Asrenee AR, Wan Emilin WMA: Magnitude and risk factors for postpartum symptoms: A literature review. Journal of Affective Disorders 2015, 175:3452.http://doi.org/10.1016/j.jad.2014.12.041

32. Eisenach JC, Pan PH, Smiley R, Lavand'homme P, Landau R, Houle TT: Severity of acute pain after childbirth, but not type of delivery, predicts persistent pain and postpartum depression. Pain 2008, 140(1):87-94.http://doi.org/10.1016/j.pain.2008.07.011

33. Ding T, Wang DX, Qu Y, Chen Q, Zhu SN: Epidural labor analgesia is associated with a decreased risk of postpartum depression: a prospective cohort study. Anesth Analg 2014, 119(2):383392.http://doi.org/10.1213/ANE.0000000000000107

34. Xia B, Chen C, Zhang H, Xue W, Tang J, Tao W, Wu R, Ren L, Wang W, Chen G: Chronic stress prior to pregnancy potentiated long-lasting postpartum depressive-like behavior, regulated by Akt-mTOR signaling in the hippocampus. Sci Rep 2016, 6:35042.http://doi.org/10.1038/srep35042

35. Bayrampour H, Tomfohr L, Tough S: Trajectories of Perinatal Depressive and Anxiety Symptoms in a Community Cohort. J Clin Psychiatry 2016, 77(11):e1467e1473.http://doi.org/10.4088/JCP.15m10176

\section{Figures}




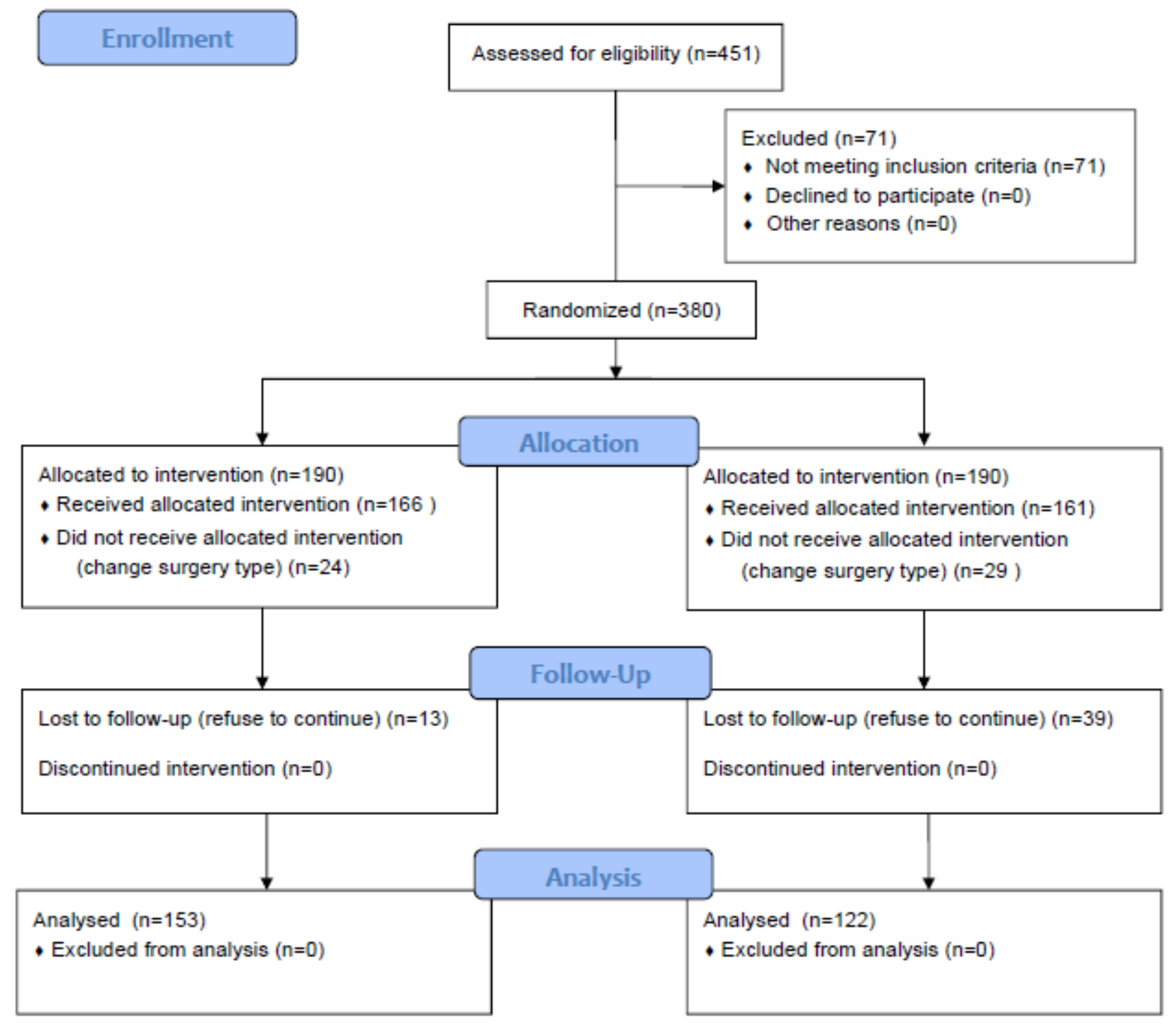

\section{Figure 1}

$<p>$ Flow Diagram $</ p>$ 


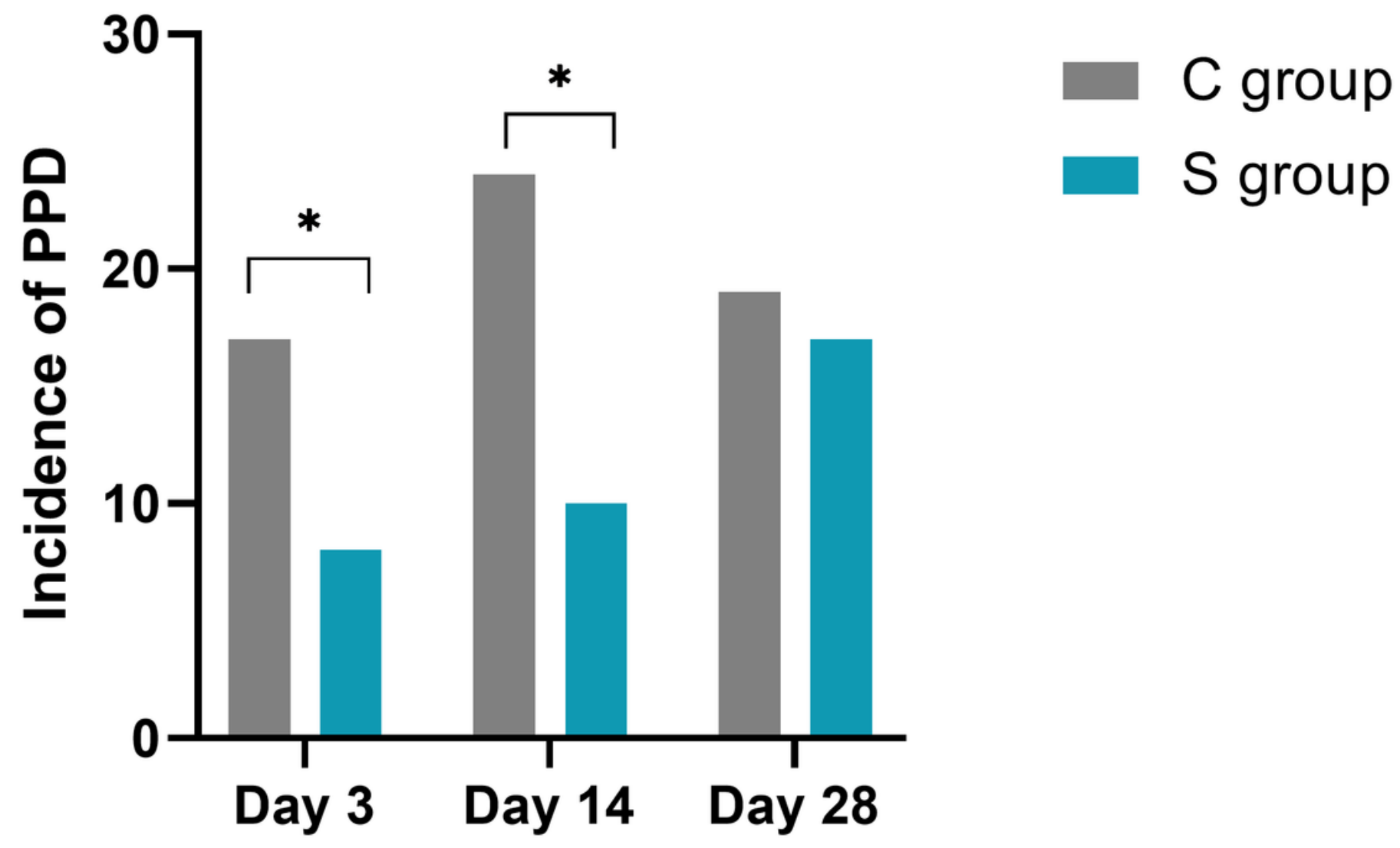

Figure 2

$<p>$ The incidence of PPD after cesarean section $</ p><p>*$ : P『0.05; Day 3 Day 14, and Day 21 refers to 3 days, 14 days, and 28 days after surgery. $</ p>$

Figure 3

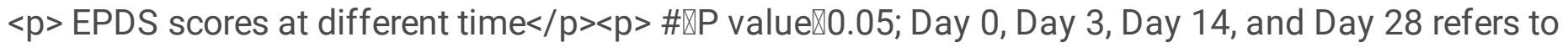
before cesarean, 3 days, 14 days, and 28 days after cesarean. $</ p>$

Figure 4

$<p>$ VAS(4a) and RSS(4b) scores at different times during using PCIA. $</ p><p>* *: P \unrhd 0.05, T 1, T 2, T 3, T 4$, and T5 means 4h, $8 \mathrm{~h}, 12 \mathrm{~h}, 24 \mathrm{~h}$, and $48 \mathrm{~h}$ after they begin using PCIA. $</ \mathrm{p}>$ 